\title{
TOURISM DEVELOPMENT IN THE STATE OF KERALA, INDIA: A STUDY OF DESTINATION ATTRACTIVENESS
}

\author{
Manoj Edward ${ }^{\mathrm{a}}$ and Babu P. George ${ }^{\mathrm{b}}$ * \\ a Cochin University of Science and Technology, India, e-mail: manojed@cusat.ac.in \\ ${ }^{\mathrm{b}}$ University of Southern Mississippi, USA, e-mail: Babu.George@usm.edu \\ ${ }^{*}$ Corresponding author
}

\begin{abstract}
This paper describes the context and framework for assessing destination attractiveness of Kerala, an emerging tourism destination in a developing country. The study reveals its strengths and weaknesses from the demand side perspective and suggests a number of valuable implications for destination marketing efforts. Comparing an array of attractions and experience elements for the destination of Kerala, the analysis highlights the importance of specific destination attraction elements as core appeals of the destination. The analysis provides a solid theoretical rationale for the spectacular performance of Kerala tourism in recent years across a number of fronts. However, negative gaps have been observed for a few vital attraction elements, broadly suggesting the need for modifying area specific development efforts to enhance the tourists experience with these attraction elements. Based on the findings of the study, the need for a moderately different emphasis in guiding both the product and promotional development activities were identified. In addition, this paper gives a glance into the development and prospects of tourism in the state of Kerala.
\end{abstract}

Keywords: Kerala tourism, Destination marketing, Importance-Performance Analysis, Strategic Implications

\section{Destination Attractiveness: An Introduction}

Destination attractiveness may be defined as the degree to which destinations meet the touristic expectations of its visitors in terms of dimensions like recreational opportunities, food and accommodation, cultural richness, natural beauty, and various other amenities (Pearce, 1979). In addition, there are many factors that cannot be strictly classified as attractions but contribute to the attractiveness of a destination: exchange rate, political risk, calamity preparedness, infrastructure, etc (Ferrario, 1979). Attractiveness is the sum of perceptual beliefs, ideas, and impressions about a destination based on information processing from a variety of sources over time, notes MacKay and Fesenmaier (1997). For Gunn (1994), attractions constitute the energizing 
power of the tourism systems. Attraction is the perceived ability of the destination to deliver individual benefits. More than anything else, it is the attractiveness of a destination that encourages people to visit and spend time there and is the basis of true tourist loyalty to a destination. Destination attractiveness plays a vital role in determining destination competitiveness, too (Buhalis, 2000).

Although the topic of destination attractiveness has become one of the most popular in the tourism research literature (Pike, 2002), the chemistry of destination attractiveness is complex and its underlying logic remains under-explained. Academic explanations of destination attractiveness have popped up for destinations that are popular; but, these explanations are found to fail as normative tools for tourism planning and policy elsewhere. This could probably be due to the fact that most of the available measures of attractiveness are developed too generically so as to capture some elusive and universally applicable attractiveness. Due to some reason or the other, an operational definition of attractiveness is conspicuously missing from the traditional modeling of the tourism system, notes Nyberg (1995). However, the study of availability and utilization of existing tourism related resources is a critical stage in the attractiveness of any destination (Gunn, 1994). For a place to have tourism potential, it is not enough to have some resources: their identification as tourism resources and the effective utilization of these resources are equally important (Formica and Uysal, 2006). Destination marketers give touristic meanings to the resources and communicate these meanings to the various tourist segments.

Technically, attractiveness can be measured by studying the attractions or by studying the attractiveness as perceived by those who are attracted by them. Even so, many scholars have contended that attractiveness is not some objective quality possessed by destinations: a destination is attractive if and only if the tourists who visit that destination feel that it is an attractive destination (Hu and Ritchie, 1993). If this is true, inventorying and weighing the tourism resource base possessed by a destination to measure the attractiveness of that destination has little consequences (George, 2005). Since tourism attractiveness is dependent on the personal benefits of visitors and on the perceived delivery of those benefits (Mayo and Jarvis, 1981), a gap between these two could be treated as a better proxy of destination attractiveness. A technique commonly used to operationalize this is to list the resources possessed by a destination, seek from tourists the importance of these resources in defining the attractiveness of that destination, and subsequently get their ratings on how much the destination performs across each of these important dimensions. This is an adaptation of the generic Importance-Performance Analysis (IPA) used by marketing researchers. This technique blends in subtle ways the demand and supply analyses independently used by tourism researchers to assess destination attractiveness. This method meets the recommendation of Formica and Uysal (2006) that the analytical techniques to measure the development of attractiveness should aim to combine the evaluation of 
existing resources and their perceived attractiveness. In the present paper, the authors present an assessment of the tourism attractiveness of Kerala by employing a combination of the IPA technique and a content analysis of relevant documents.

\section{Kerala: Tourism Development and Tourism Policy Framework}

Kerala lies on the southwest coast of the Indian Peninsula, stretching 360 miles $(580 \mathrm{~km})$ along what is known as the Malabar Coast and has been noted by many as a paradise of tourism. Kerala is a prime high-end tourism destination in the Indian subcontinent and has been rated as "one of the fifty destinations to be visited in one's lifetime” by the National Geographic Channel (2004). Moderate climate, rich art, colorful festivals, diverse natural and cultural attractions with a physical quality of life comparable to developed nations are causing the tourism industry to flourish in Kerala. Compared to the other states in India, Kerala is unique for its interesting geographical diversity it possesses within the smallest area possible. This diversity offers tourists a rage of attractions and experience such a beaches, backwaters, wildlife sanctuaries, evergreen forests and diverse flora and fauna of Kerala. It is often projected as the "Green Gateway" to India (Netto, 2004). The tourism map of Kerala is given below (Figure 1):

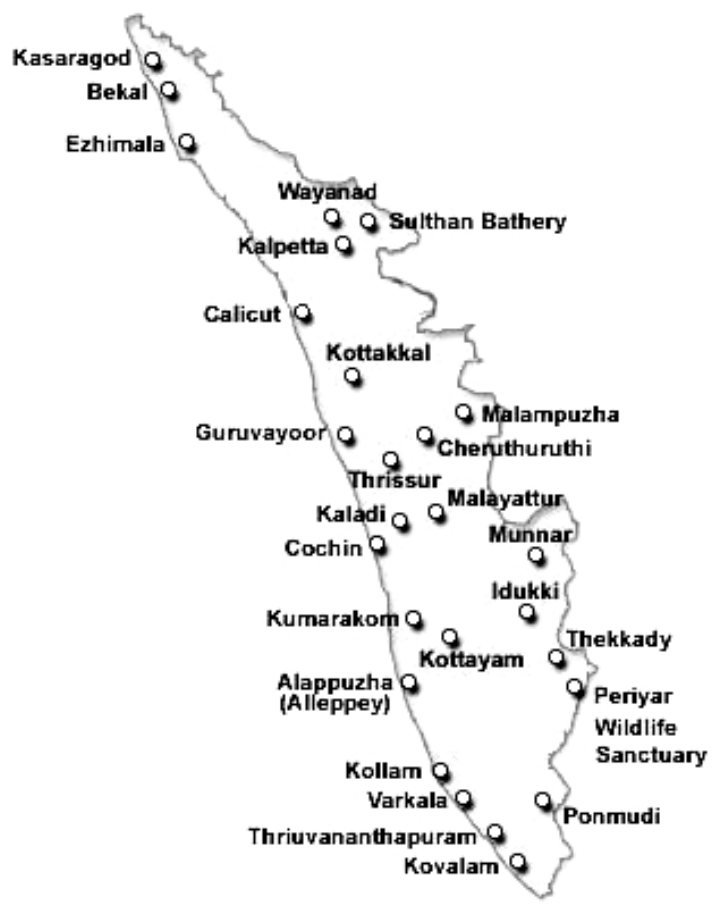

Figure 1 Tourism map of Kerala 
Tourism has emerged as a lead sector of the Kerala economy, with its impact increasing in terms of economic growth and employment generated (GOK, 2002). The state government views tourism as one of the few alternatives available to develop the economy, especially in the context of limited prospects of the manufacturing sector, problems in the agricultural and traditional sectors, and the uncertainties facing expatriate employment in the Persian Gulf (Pushpangadan, 2003). Kerala is now considered to be a tourism model for other states in India to emulate its growth. The tourism industry in Kerala witnessed considerable growth during nineties and beyond and is expected to grow further in the future.

Kerala's share of international tourists coming to India has increased from 5.54 percent in 1994 to $8.85 \%$ percent in 2005 making it a leading state for tourism in the country. Earnings from tourism is also projected to grow at a record level of more than 23.5 percent which is very high compared to earnings growth projected for India and world average which is 14.3 percent and 6.5 percent, respective. During this same period, tourism receipts from international tourists also grew considerably, from 1.16 billion rupees in 1994 to 19.89 billion rupees in 2006 (GOK, 2006a). International tourist arrivals to Kerala had reached almost half million in 2006, and is expected to cross 500000 by 2007. For the domestic tourism, the arrivals had crossed 6 million in 2006. This almost meets the prediction of world Travel and Tourism Council (WTTC) that with an average annual arrival growth rate of $18 \%$ for domestic tourists and $12 \%$ for international tourists Kerala is becoming one of the fastest growing destinations in the world (WTTC, 2002). The growth of domestic and international tourism in Kerala and its relative position in the Indian tourism in the recent past is depicted in tables 1.1 and 1.2 .

Table 1.1 International \& Domestic Tourists Arrivals

\begin{tabular}{|c|c|c|}
\hline Year & International tourists & Domestic tourists \\
\hline 1994 & 104568 & 1284375 \\
\hline 1996 & 176855 & 4403002 \\
\hline 1998 & 189941 & 4481714 \\
\hline 2000 & 209893 & 5013221 \\
\hline 2002 & 232564 & 5568256 \\
\hline 2004 & 345546 & 5972182 \\
\hline 2006 & 428534 & 6271724 \\
\hline
\end{tabular}

(Source: Department of Tourism, Government of Kerala, Tourist Statistics, 1994, 1998, 2002, 2006) 
Table 1.2 Kerala's share of foreign tourists to India

\begin{tabular}{|l|l|l|l|}
\hline Year & India & Kerala & \% Share \\
\hline 1994 & 1886433 & 104568 & 5.54 \\
\hline 1996 & 2287860 & 176855 & 7.73 \\
\hline 1998 & 2358629 & 189941 & 7.68 \\
\hline 2000 & 2649378 & 209893 & 7.92 \\
\hline 2002 & 2384364 & 232564 & 9.75 \\
\hline 2004 & 3367980 & 345546 & 10.26 \\
\hline
\end{tabular}

(Source: Department of Tourism, Government of Kerala, Tourist Statistics, 1994, 1998, 2002, 2004)

Tourism is also counted as an important alternative to address unemployment, which is a major problem facing the state (Kokkranikal and Morrison, 2002). Further reasons making the tourism industry attractive for the state include its strong linkages with other sectors in the economy and its potential for generating benefits more widespread throughout the state for any given level of capital investment compared to other sectors. A study done by the Tata Consultancy Services shows a strong multiplier effect for the tourism industry in the state for both the output multiplier and the employment multiplier (TCS, 2000). With regard to employment generation in the state, the travel and tourism industry is expected to create 750000 jobs in the next 10 years and the broader impact of it on economy can create 1.4 million jobs during this period (WTTC, 2002).

Kerala is one of the earliest Indian states to announce industry status for tourism in 1986 and announce various incentives and subsidies to attract investment (Rao and Suresh, 2001). This increased the investment opportunities for potential investors. Major lending institutions like KFC (Kerala Financial Corporation), TFCI (Travel Financial Corporation of India), and KSIDC (Kerala state industrial development corporation) played important roles in funding various tourism projects. The state also adopted many proactive measures to stimulate investment in the tourism industry like a system for fast track clearance of tourism projects, subsidies, technical guidance, marketing assistance and support in availing loans (GOI, 1998).

The shift in emphasis of the state's tourism department to a more proactive role of tourism development and marketing and promotion of the destination started in the early nineties (Kokkranikal and Baum, 2002). The first tourism policy that came out in 1995 spelled out the major direction for the growth of the industry. For the first time, the key role played by the private sector in all these areas was identified in addition to defining the role of state as a facilitator in creating the suitable condition for investment. Priority areas identified were infrastructure development, human resource development for tourism, marketing and product development (GOK, 1995). 
Thereafter this tourism policy remained the basis for much of the state's progress over the last 10 years; whether in terms of infrastructure, product development, or tourism performance (WTTC, 2002).

For the first time the manner of growth needed was also envisioned in the first tourism policy, i.e. promoting destination more as a high quality destination, attracting high spending tourists rather than going after mass tourism (GOK, 1995). This conscious strategy of taking the destination Kerala away from mass tourism to a destination with a boutique image attracting tourists of a specific taste required developing uniquely new tourism products and destination regions. Diversifying to new products was a vital part of the tourism strategy of differentiation, given that other nearby states and neighboring countries like Srilanka and Maldives were offering the same kind of products. So in addition to beaches, Kerala as a destination started developing and promoting varied tourist products like backwaters with house boat attractions and Ayurvedic rejuvenation holidays. The first tourism policy also highlighted the need for creating competent human resources to serve the growing needs of the industry to promote quality tourism (GOK, 1995).

The stated objective of the state government is to promote Kerala more as a quality destination, attracting high spending tourists rather than mass tourism chasing numbers (GOK, 1995). This conscious strategy required developing new tourism products and new destination regions. Varied tourism products like backwater attractions and ayurvedic rejuvenation based attractions have helped to acquire a unique image in the international and domestic markets.

Despite setting the direction for growth in the tourism industry, the initial tourism policy framework of the state was not sound in detail; it lacked in providing a detailed action plan for the destination to grow. The government came out with a new policy document titled "Vision 2020" in the year 2000 which was more comprehensive and highlighted sustainability concerns along with tourism growth (Kerala Tourism, 2007). Among others, it reflected the growing concern for environmental conservation, heritage and culture protection, lack of basic infrastructure surrounding major destinations, and the need for proper quality assurance systems and legislations to regulate and bring quality in tourism. It also stressed the need for integrated development of infrastructure with special tourism zones so that the pristine quality of the environment is preserved. The new policy aimed to make tourism Kerala's core competency sector and gave special emphasis on enhancing the employment potential of the sector. This was expected to alleviate poverty and make tourism the most important sector for the socio-economic development and environment protection of the state. Apart from reiterating the role of the government as a facilitator for the growth of tourism industry, it has also identified the need for the state to come up with regulations for directing the growth of tourism in the right direction (Netto, 2004). 


\section{Product Development and Destination Marketing}

From the first tourism policy onwards there was a continuing emphasis on developing new products or new destinations every year. This is part of the tourism strategy to develop the image of an up-market high quality destination aiming at high spending discerning travelers who seek unique experiences from the destination. Increasing the appeal for ayurvedic rejuvenation holidays and heritage attractions in the international and domestic markets and expanding variety in the accommodation provision of boutique resorts and heritage hotels were some of the landmarks in the successful product development efforts in the tourism industry of Kerala. It is about this aspect of the destination, eclectically blending the culture and ethos with architecture and design, that National Geographic reported as being one of the best in the world. Initiatives taken by the state government for converting old buildings of traditional Kerala architecture (traditional nalukettus and tharavadus) to heritage type accommodation properties added further to this image.

Enhancing the appeal of tourist attractions with suitable product innovation came up in many forms. For instance, Traditional ketuvallams (country boats) converted into improved and uniquely designed house boats with modern facilities offered tourists a unique experience of backwater attractions. Innovations were also seen in developing unique tourism packages with niche attractions: Thekady Tiger Trail developed in collaboration with forest department involving $25-30 \mathrm{~km}$ of trek through the wild life sanctuary; and 'a day with masters', a tourism package that enabled tourists to experience intensely traditional art forms like Kathakali, Kodiyattom and Theyyam, spending time with great masters in these art forms (Kerala Tourism, 2007).

Initiatives for creating a variety of tourism products offered tourists an enriching experience of Kerala. Such initiatives were either to enhance the existing tourist attractions or to develop new attractions. Tourism packages developed around plantations sector, 'avian' tourism to attract bird watchers, and developing tourism packages to promote Kerala as a Meetings Incentives, Conventions and Exhibitions (MICE) destination are few noteworthy initiatives. Another initiative was to link tourism and the environment by means of the development of ecotourism. This project has come up in Thenmala, in the Western Ghats, where activities such as trekking through rain forest and staying in tree top huts are organized. Kerala is probably the first planned ecotourism destination in India, implemented with the support of forest department and the local community (Kerala Tourism, 2007).

One area the state performed well is the promotion and marketing of the destination. This was achieved through focused marketing efforts during the last 10 years. There were also efforts in branding the destination along with the focused promotional strategies around the theme "gods' own country". In a way this has resulted in creating a boutique image for the destination in the various generating 
markets. These efforts helped to differentiate the destination from the other states of India as well. During this period, Kerala took the bold initiative of participating with its own pavilion in key international travel fairs in Europe and west Asia, which are the key markets for the destination. Attending independently such important travel fairs enabled the marketing Kerala directly to key intermediaries such as international tour operators, airlines and travel media for increased visibility in the clutter of global tourism map (WTTC, 2002). In this process, Kerala as a tourist destination has evolved into a brand of its own. Kerala is listed among the top 100 brands of the world by the globally renowned super brands Ltd. Another high impact marketing initiative was the launch of Kerala Travel mart (KTM) in 2000 which is now India's premier international travel mart. KTM 2002 saw the participation of trade from the new markets like USA, Denmark, Greece, Ireland, and Sweden. With these efforts, destination Kerala has started getting noticed in the global tourisms map even as a stand alone destination. This is also reflected in the release of a Kerala exclusive guide book from the widely referred travel guide Lonely Planet. Wide acclaim from reputed travel magazines like National Geographic, Condi Nast Traveler, and the endorsement of the destination by high profile celebrities have helped greatly to create a favorable image for Kerala in the generating markets.

Promotional initiatives also relied on media like web and direct marketing route. A highly interactive website, road shows in selected international and domestic markets, high quality brochures and CDs as promo materials were some of the additional promotional initiatives which reflect the strategic approach to marketing the state undertook. These promotional efforts combined with participation in international travel fairs in key markets created a synergistic effect in attracting both the international and domestic tourists to the state (TCS, 2000).

Private sector participation in all platforms - whether in policy making, promotion and product development was a distinctive feature of tourism development pursued in Kerala (WTTC, 2002). In fact KTM, the mega marketing event of the state for tourism (the initiative of the private sector, conducted in partnership with the government), demonstrated the active involvement of private sector in the tourism planning and development activities. Clearly, the many levels of cooperation and partnerships developed between the government and various other stakeholders formed the basis for many tourism development efforts: public- private sector joint venture for infrastructure development; joint marketing efforts with other southern states; committees for coordination between departments; enabling an investment climate; tourism related facilities and services improvement; and district tourism promotion councils for decentralization of tourism development (Kerala Tourism, 2007).

Quality assurance and control efforts were also targeted for major tourism products like house boats and ayurvedic rejuvenation centers and hotels. This included gold and star certifications for houseboats based on materials used for their 
construction, facilities offered by them, the quality of furniture, services, and the safety and security measures. To promote eco friendly measures among houseboats, 'Green Palm' certification has been launched. To ensure the quality, safety, and service standards of the ayurvedic centers, 'Green Leaf' and 'Olive Leaf' certifications are being given based on the evaluation of the authenticity of the treatment provided, the training of the staff, the conveniences and amenities, and the quality of furniture (TCS, 2000). Another certification scheme launched is to certify hotels as 'STEP' (Safe-ToEat Places) certification based on their hygiene and quality standards in the preparation and serving of cuisine. In addition to improving the quality of the core attractions, the government has taken initiatives to improve facilitation services including the expansion of tourism information centers and convenience facilities such as toilets, communication and related services at all important locations (Kerala Tourism, 2007).

\section{Destination Attractiveness Assessment Using IPA Technique}

Systematic approaches to quality measurement with easy to use and reliable measures are important for service firms, especially when there are fewer objective measures of quality by which to judge their production (Hudson and Sheppard, 1998). This will help managers to better know which aspects of a service best defines its quality and can prepare the organization to take up a competitive position based upon its ability to deliver what customers demand (Cronin and Taylor, 1992).

In response to the growing importance of service quality as a means of gaining competitive advantage, researchers have developed more detailed attribution techniques aimed at measuring customer perceived service quality within the services sector (e.g. Parasuraman et al., 1985; Cronin and Taylor, 1992). The majority of these studies have adopted the expectation-disconfirmation paradigm, which defines quality as the confirmation of performance with expectation. The most popular application of this approach is the development of SERVQUAL instrument by Parasuraman, et al., (1985). Despite its popularity, SERVQUAL instrument has limitations due to its generic dimensions, which have not been found to be consistent across industries. Furthermore, the practical difficulty of assessing expectations and performance separately, and the complexities regarding the nature of how expectations are formed (Brown et al., 1993; Zeithaml et al., 1993) limits its usage. The need to simplify and improve the reliability of the measurement of service quality has led researchers to develop more direct approaches using performance-only based measures of service quality. Principal amongst these is the development of the SERVPERF technique (Cronin and Taylor, 1992).

Another direct measurement technique is the Importance-Performance analysis (IPA) which emerged from the earlier work of Martilla and James (1977). This technique is also called Key Driver Analysis. Unlike SERVPERF, the ImportancePerformance technique allows simultaneous comparisons of direct performance 
measures of service quality to the importance ratings given by customers for the various quality items being evaluated. The inclusion of customer preference rating in IPA gives a better picture of customers' quality assessment of the product or service. According to Barsky (1995) such assessments pinpoint clearly the quality aspects of the product or service that contributes greatly to customer satisfaction. The resulting information derived out of IPA can aid the development of more focused marketing strategies (Ford et al., 1999). This view is confirmed by Lovelock et al. (1999) who state that importance-performance analysis is a useful management tool which can help firms to redirect their scarce resources from low impact areas to high impact areas. IPA has a solid foundation built upon multi-attribute models, notes Keyt et al. (1994). According to Wade and Eagles (2003), IPA is the simplest of all valid techniques in its category and has shown the capability to provide tourism managers with valuable information for both satisfaction measurement and the efficient allocation of resources. It has a relatively rich history of application in the tourism research, as well (Duke and Persia, 1996; Martin, 1995; Uysal, 1991).

In the importance performance analysis, perception and importance values are plotted on a grid that is divided into 4 quadrants, formed based on the mean scores of the importance perception ratings. The values are then assessed according to its position in the quadrant on the grid. Each quadrant suggests different responses from a marketing strategy point of view. Attributes that are rated high in importance and high in performance suggest that service providers keep up the good work; this also suggests increasing resources directed towards these areas. In contrast, attributes having low importance rating and a low performance rating suggest that investing resources to these areas may offer only little advantage. Attributes that are rated high in importance and low in performance are areas that the providers should pay particular attention for improvement. Lastly, attributes rated low in importance and high in performance are areas providers should continue to maintain the level of effort. The utility of IPA is that it can help businesses understand what its customers feel is important across a number of relevant variables.

Researchers have used IPA framework for service quality research in travel and tourism (Evans and Chon, 1989; Go and Zhang, 1997, O’Neill et al., 2002). Most of these studies assessed service quality for specific tourism products. As an extension of its use, this study attempts to use IPA for evaluating international tourists' perceived destination attractiveness for Kerala. In this regard, destination attractiveness is represented in terms of various tourist attractions and experience elements identified in the qualitative phase of the study, for its inherent appeal to attract tourists to the destination in the first place. Many destination elements like safety, access, transportation, information provisions were not included in this study, because these elements rarely attracts tourists to a particular destination even though they can influence the tourists' holiday satisfaction to an extent. 


\section{Research Method}

The research followed a two-stage methodology, comprising qualitative and quantitative stages. The qualitative stage involved the analyses of various brochures, interviews with experts from the tourism industry, and an unstructured survey with tourists as part of knowing the various relevant destination attraction and experience elements relevant to the Kerala holiday experience. The various characteristics of the destination were jointly treated as attraction elements (Scott et al., 1979). This information was then used for the subsequent quantitative study carried out using a structured questionnaire.

The state as a whole was the unit of analysis. Unless there are other constraints, given the present organization of political governance in most democracies, states provide a better unit of measurement of destination attractiveness than other units like regions, countries, and country groupings. If one does not want to identify sub-areas that have higher or lower attractiveness potential, states provide an excellent unit for attractiveness studies (Lawson and Bovy, 1977). Respondents selected were international tourists departing through the two international airports in the state: Cochin and Trivandrum. The control over the sample was exercised by limiting the number of tourists surveyed in a day and by selecting respondents at different time of the day. This was important since the diagnostic sensitivity of the IPA technique is limited to the diversity of visitor segments identified in the sample. Finally, around 400 responses were obtained for analysis.

Ideally for a study of this type, destination attribute importance needs to be measured prior to, rather than after, an actual purchase experience. But due to the practical difficulty in meeting tourists prior to the visit, importance ratings are taken at post consumption stage. Performance is then measured using the same set of attributes so that importance and performance of the destination can be directly compared for each attraction via the IPA plot (or grid). The mean values of importance and performance scores are then used as the crossing point in constructing the IPA grid.

The horizontal axis in the IPA grid indicates tourists' perception of the destination attraction and provisions measured in a 5 point impression rating scale. The vertical axis indicates the importance for the same destination attraction and provision elements measured in 5 point importance rating scale. Tourists' perception rating and the importance rating for the fifteen destination attributes and activities used as inputs for the IPA is presented in Table 2. 
Table 2 Importance-Performance Means

\begin{tabular}{|l|l|l|}
\hline \multicolumn{1}{|c||}{ Destination Attraction } & Mean Importance & Mean Performance \\
\hline \hline Beaches & 4.11 & 2.83 \\
\hline Wildlife & 3.47 & 2.57 \\
\hline Climate & 4.34 & 3.38 \\
\hline Ayurveda & 3.00 & 3.09 \\
\hline Cuisine & 4.04 & 3.21 \\
\hline Heritage sites & 3.66 & 2.34 \\
\hline Art/craft forms & 3.79 & 2.86 \\
\hline Hill stations & 3.02 & 3.10 \\
\hline Backwaters & 3.81 & 3.47 \\
\hline Shopping & 3.14 & 2.46 \\
\hline Nightlife & 2.22 & 2.07 \\
\hline Adventure \& fun activities & 2.71 & 2.44 \\
\hline Rest and relax environment & 4.5 & 3.13 \\
\hline Accommodation standards & 3.4 & 2.73 \\
\hline Local culture & 4.4 & 2.95 \\
\hline
\end{tabular}

The fifteen attributes were taken as a basis for the destination attractiveness evaluation. Apart from using general attractions like climate and local culture, tourists' impressions with specific attractions like backwaters, hill stations, and auyrvedic rejuvenation experience offered at the destinations were included for assessing the destination attractiveness. As the assessment of destination attractiveness is from the tourist perspective, only tourism specific attractions and activities were included in the IPA.

The study included both controllable and uncontrollable destination attributes. This is in contrast to many service strategy formulation studies using IPA, where the 
general practice is to include only controllable variables. In such cases, IPA is used as a prescriptive tool for directing or redirecting resources to different service quality areas. In this study, the focus being on assessing destination attractiveness quality of a destination, both controllable and uncontrollable factors are used. For example, attributes like local culture and many natural attractions like wildlife and hill stations are difficult to improve beyond a level for they are resources given for developing tourism. Such attributes are included in this study because here IPA is used as a descriptive tool to understand the destination attractiveness. As a descriptive tool, IPA is used both for indicating the need for improvements in some key destination areas, as well as to reveal the less controllable destination attraction elements on which destination promotion and positioning activities can be based. Another reason for such a choice is that most of the attributes used in this study are assessed at an aggregate level.

The average level of tourist rating with various attractions of Kerala and the average importance of the attractions for tourists were calculated for the whole sample. As part of assessing the destination attractiveness matrix, these mean scores were plotted in an Importance - Performance rating matrix as shown in figure 2. The grand means for performance $(\mathrm{x}=2.95)$ and importance $(\mathrm{y}=3.5)$ determine the placements of axes on the grid. Each attraction is then assessed by locating in the appropriate quadrant. Tourists' perception and importance values are plotted on the grid that is divided into 4 quadrants that are formed based on the mean scores of the importance perception ratings. These values are then assessed according to the quadrant on the grid it is placed. Each quadrant suggests a different response from the destination marketing strategy point of view.

Destination Attractions and provisions that are rated high in importance and perception scores are areas of strength for the destination appeal and consequently the destination marketing activities can focus more on these elements. Areas having low importance rating and a low perception rating indicate destination attractions which can be regarded as peripheral to the core destination appeal, and therefore require less of destination development and marketing efforts. Attractions and provisions that are rated high in importance and low in perception are areas that destination marketers should pay particular attention for development and repositioning in the destination marketing activities. Lastly, areas rated low in importance and high in perceptions are attractions where destination marketing can continue to maintain the same level of effort because of the relatively less scope for enhancement in the level of tourists' satisfaction through additional effort in these areas. 


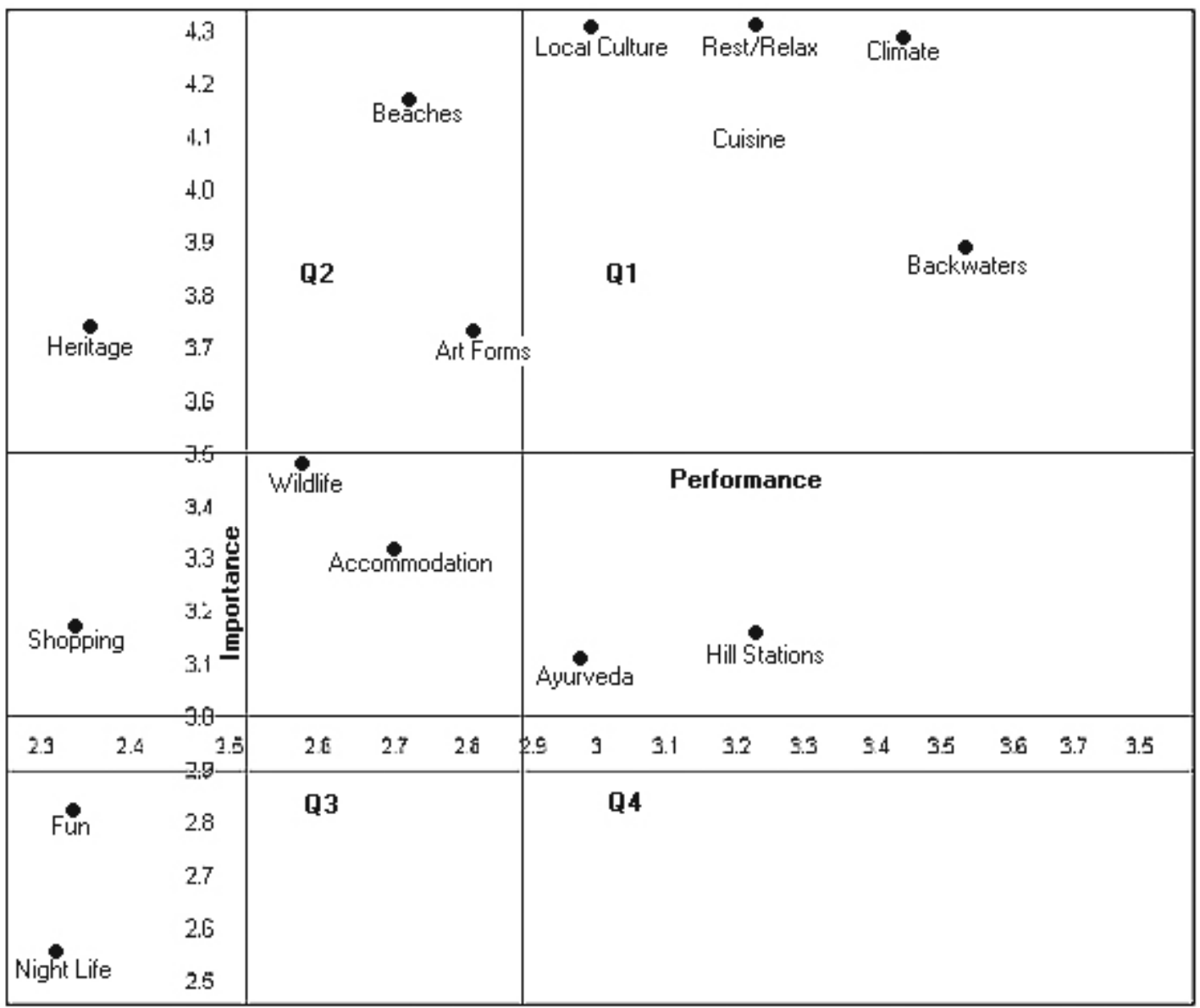

Figure 2. Importance-Performance Matrix

\section{Analysis and Discussion}

Plotting destination attractions and experience elements in an importance performance matrix revealed that climate, backwaters, local cuisine, rest and relax environments, and local culture falls in the quadrant 1 (high important and high impression). As destination attractiveness elements, these attributes can be viewed as the strength of the destination appeal for the international tourist market in Kerala, and suggest key areas on which destination marketing activities can be further developed. What is interesting is the representation of local cuisine as an important dimension of destination quality assessment, and furthermore its significance suggests that this attraction can be further highlighted in the destination promotion activities. Similarly, the presence of backwaters, local culture, rest and relax environments in this quadrant 
projects certain unique characteristics determining core appeal of the destination, which can be further packaged effectively in the destination positioning exercises.

Destination attraction elements falling in quadrant 2 (high important and low impression) are beaches, art and craft forms, heritage attractions; these are destination attraction areas where destination development and marketing efforts need more attention to turn them into areas of perceived strengths for the destination. Comparing the relative positions of the attractions in this quadrant, reveals that beach attractions being placed higher in the quadrant offers more potential in improving the destination attractiveness for Kerala. Therefore, beach attractions, one of the important attractions for the destination, needs more attention in development and marketing for enhancing the quality of beaches and its appeal. Though somewhat less in significance, other attractions like art forms and heritage sites, identified by their position in IPA matrix, too need further improvement in their development and therefore should form an important part of destination development activities for Kerala to attract international tourists.

Destination attractions and elements which fall in the quadrant three are wildlife attractions, accommodation standards, shopping, nightlife and adventure \& fun activities (low importance and low impression). At an aggregate level of assessment, these destination quality elements appear less significant for enhancing the destination appeal for international tourists compared to other attractions in quadrant 1 and quadrant 2. This finding, especially with regard to accommodation, appears contradictory to some of the insights obtained during the initial qualitative stage of study using interviews with tourists and managers where the importance of accommodation was repeatedly highlighted by the respondents. It is also possible that the true nature of importance of some of these attributes may be masked in this IPA analysis. In fact, some of these attractions and provisions, especially accommodations, can be more of dissatisfier than as a satisfier, that is, a drop in the performance level of these provisions may significantly alter the tourists' satisfaction levels. The lower position of nightlife and adventure/fun activities in this quadrant clearly indicates that these areas are les important as far as Kerala is concerned and therefore needs less effort as part of destination development activities, compared to other areas of attractions. However, using proper segmentation studies, the potential to attract particular segments of tourists with high preference for these attractions needs to be further explored.

Lastly, destination attractions spotted in the quadrant 4 (low importance, high impression) are ayurvedic rejuvenation attraction and hill stations. The indication is that at an aggregate level of assessment as destination attraction elements, they are perceived better than what is expected. Nevertheless, the possibility of unique segments of tourists who seek high levels of quality from ayurvedic rejuvenation 
experience and hill station attractions may necessitate the importance of taking initiatives to improve quality in these attractions.

\section{Conclusion}

This present paper reported an attempt to assess the destination attractiveness of Kerala, an emerging tourism destination in India. The destination attractiveness study has revealed the strengths and weaknesses of Kerala from the demand side perspective, which suggests implications for destination marketing efforts. Comparing an array of attractions and experience elements for the destination of Kerala, the analysis highlighted the importance of specific destination attraction elements as core appeals of the destination. The analysis provides a solid theoretical rationale for the spectacular performance of Kerala tourism in the recent years across a number of fronts. Yet, negative gaps were observed for a few vital attraction elements, broadly suggesting the need for modifying area specific development efforts to enhance the tourists experience with these attraction elements. Based on the findings of the study, the need for a moderately different emphasis in guiding both the product and promotional development activities have been identified. In addition, this paper gives an overall view of the development and prospects of tourism in the state of Kerala.

Understanding tourists’ preferences and their perception of the destination are considered essential inputs in tourism planning and marketing efforts (Kotler et al., 2005). Formulation and implementation of effective destination marketing strategies requires careful assessment of existing destination attraction elements from a demand side perspective (Heath and Wall, 1992). For this, in the present paper, a destination resource analysis, identifying the key positions of each attraction elements and the destination attraction elements that can have the most impact on the performance of a tourist destination has been done. Many regions in developing countries have limited resources available for destination marketing and therefore it is important to identify the key attractions which can be considered as vital for attracting tourists which can significantly enhance the tourists appeal for the destination. This aspect gains significance particularly for tourism destinations with a range of attractions who find it difficult to select and combine the destination attraction attributes in suitable combination for effective positioning. The present study identified specific tourist attractions in certain combinations, which can be effectively combined and jointly promoted in the positioning exercise for an attraction rich but marketing resource limited destination like Kerala.

The present study is helpful for tourism decision makers in the public and private sectors to understand the potential and development strategies of tourism in Kerala. Its findings will provide inputs for planning, marketing, and developing appropriate resource allocation strategies. This study is a powerful input for destination promotion and positioning activities. Tourism bodies at the local level might find the 
study useful to locate areas where tourist services or facilities are underdeveloped based on their attractiveness potential and encourage the firms therein to allocate more resources. The study can be used as means of persuasion in addressing tourism development issues in the destination communities, too.

With the simultaneous consideration of tourists' assessment of the importance of salient attributes for the destination experience and their level of impression with the destination attributes, we have used the IPA to associate tourists' destination quality perception and their requirements. Being focused on an overall assessment of the total destination experience, destination attractions and provisions are measured at an aggregate level. Nevertheless, as a starting point, this is sufficient to provide the essential insights on destination attractiveness as perceived by the tourists. The analysis has revealed the strengths and weaknesses of the destination from a demand side perspective. We have discovered that most of the attraction elements that are considered as important by the international tourists visiting the state have an above average performance rating, too. In the light of the above discussion, this is not something strange. In fact, the competitive advantage of Kerala is inimitable to a very great extent: for example, climate, culture, backwaters are rated as important attraction elements; they are also superior in performance. There are a few items in the fourth quadrant, which essentially means that the state should not be committing much of its limited promotional budget to promoting them. Instead, more attention should be focused up on promoting the beaches and the state's heritage: these are greatly expected, but low in performance. Kerala is a coastal state and beaches are one of its biggest assets. One reason why beaches do not perform up to expectations could be that the state government downplays beach tourism. Kerala wants to be a high end tourism destination and its government is worried that promotion of the beachside will push the state into a low end mass tourist haven. This could be a wrongly placed notion since previous research says that beach tourists visiting Kerala are high spenders; probably they spend more than those who visit in search of heritage and culture (Rajasenan and Kumar, 2002). Or, it may be that only high spending beach tourists visit Kerala due to the government's beach de-marketing efforts. These are valuable inputs for destination promotion and positioning activities.

The analysis indicated the importance of certain destination attraction elements like climate, backwaters, cuisine, and rest and relaxation environments, and local culture as strengths of the destination based on which destination promotional activities can be further reinforced. Areas where destination attractiveness gaps observed include beaches, art forms, and heritage attractions; these points need further emphasis on area specific development efforts to enhance the tourists experience with these attractions. With an array of attractions and experience elements provided at the destination, it may be useful to view the destination as a composite product, with certain attractions forming the core and the others at the peripheral, augmenting the 
tourists' experience of core attractions. In this conceptualization, attractions like nightlife, shopping and adventure activities may belong to a peripheral category; these attractions also need improvement efforts, but to a lesser extent, as compared to some of the core attractions. Overall, findings indicate the need for different strategies for guiding both the product and promotional development activities targeted for different tourism products.

It may be recalled that the destination quality attributes generated through the qualitative phase of the study included both controllable and non-controllable items. This is because, in addition to the purpose of correcting and diagnosing problems for the core destination management activities, the use of non-controllable items (culture, environment, climate etc) included in this study provide better quality assessment of the destination based on tourists' perspective, considered as a useful input for destination marketing programmes.

There are some noteworthy limitations of the study as well: as this study was done for whole of the destination, detailed evaluation of specific quality dimensions of each attraction was not evaluated. Further, as the data from the sample was aggregated, the data may only represent an overall view of destination attractiveness as perceived by the international tourists. The international tourist market to Kerala can be segmented based on various relevant segmentation variables, and destination attractiveness assessment for specific tourist segments may reveal more information regarding destination attractiveness for Kerala. Therefore, future research should focus on these areas. Future research can also be undertaken, exclusively focusing on various destination quality elements such as safety, hygiene, access, tourist information etc to identify destination service quality gaps.

As noted elsewhere, one of the issues facing destination attractiveness researchers is the generalizability of the conclusions and the replicability of the study in other contexts. Given that no two destinations are alike, researchers who attempt to get generalized findings end up getting lean and practically irrelevant findings. However, as is increasingly being recognized, context specific knowledge is no less a theoretical contribution (Flyvbjerg, 2006). For instance, the study has empirically verified the theoretically expected results of the destination marketing initiatives taken up by the state's tourism organizations and enterprises. Application of the IPA technique for destination attractiveness measurement in a developing country context in Asia is another novelty of the paper. Nevertheless, contributions of the present study to practice outweigh its theoretical contributions.

It may be noted that this study is done purely for international tourists visiting Kerala. Given the volatile international tourism environment, no sensible destination management authority can neglect the importance-performance ratings for the state's attractions given by the domestic tourists. Thus, final tourism policy outcomes should be informed by the collective viewpoint emerging from the IPAs of domestic and 
international tourist segments. As the next step, destination attractiveness assessment should be also done for domestic tourists visiting Kerala as well. Most importantly, this would help in identifying areas of overlap: these are areas where you can gain more customers with less spending.

Tourism in Kerala has been thriving for some time and the rate of change in terms of visitation and the amount spent is higher than any other state in India. During the last decade, tourism in Kerala has made a spectacular performance. From 1999 onwards, consecutively for three years, Kerala Tourism received the Best Performing Indian State award. Some of the main tourism development initiatives taken by Kerala which enabled it to become one of the leading destinations internationally are:

- Focused marketing efforts within a limited budget, developed in active partnership with private sector, leading international travel firms and agencies.

- Early lead in formulating comprehensive tourism policy, guiding and setting long term vision and goals for the tourism sector growth.

- Successful differentiation of the destination using effective positioning strategy, and benchmarking the performance with the neighboring leading international destinations, in the process, developed a distinct image as a stand alone destination from India and the rest of the states.

- Development of an array of tourism products of world class appeal mostly based on resources available locally.

Added to these, the socio-economic context of Kerala defined by a high level of social development and a contrasting industrial backwardness turned out to be a perfect setting for promoting Kerala as an unspoiled destination with exotic characteristics. In most parts of Kerala, the march from an agrarian society to the present day information society was bypassing the intermediate stage of the industrial society (Govindan, 1996).

We do not argue that a democratic state like Kerala should devise its tourism strategy purely based on the whims and fancies of tourists (Sreekumar and Govindan, 2002). There can be important priorities for the state irrespective of customer demand: for instance, Ayurveda (an alternative medical treatment) is in the fourth quadrant: marketing research may dictate that it be neglected. But, it gives employment to a lot of people and at the same time is an important reflection of the state's culture. In such cases, international market segments that do not currently patronize the state but which consider these types of products as important should be identified and cajoled with suitable promotional schemes. This is true in general: an importance-performance analysis is merely the perceptions of the currently patronizing segment. It does not mean that some attractions considered unworthy by these segments will never be sold or that these attractions need not be preserved. There could be a market segment waiting somewhere for every type of product (Levitt, 2004): real success lies in identifying and targeting it. 


\section{References}

1. Barsky, J. D. (1995) World-Class Customer Satisfaction. Chicago, USA: Irwin Publishing.

2. Bolton, R., J. H. Drew (1991) A multistage model of customers' assessments of service quality and value. Journal of Consumer Research, 17(4), pp. 375-84.

3. Brown, T. J., G. A. Churchill, J. P. Peter (1993) Improving the measurement of service quality. Journal of Retailing, 69(1), pp. 127-139

4. Buhalis, D. (2000) Marketing the competitive destination of the future. Tourism Management, 21 (1), pp. 97-116

5. Cronin, J. J., S. A. Taylor (1992) Measuring service quality: A reexamination and extension. Journal of Marketing, 56(1), pp. 55-68.

6. Duke, C. R., M. A. Persia (1996) Performance-Importance Analysis of escorted tour evaluations. Journal of Travel and Tourism Marketing, 5(3), pp. 207223.

7. Elliot, J (1997) Tourism, Politics and Public Sector Management. London and New York: Routledge

8. Evans, M. R., K. Chon (1989) Formulating and evaluating tourism policy using importance-performance analysis. Hospitality Education and Research Journal, 13(3), pp. 203-213

9. Flyvbjerg, B. (2006) Five misunderstandings about case study research. Qualitative Inquiry, 12(2), pp. 219-245.

10. Ford, J. B., M. Joseph, B. Joseph (1999) Importance-performance analysis as a strategic tool for service marketers: the case of service quality perceptions of business students in New Zealand and the USA, The Journal of Services Marketing, 13(2), pp. 171-186.

11. Formica, S., M. Uysal (2006) Destination attractiveness based on supply and demand evaluations: An analytical framework. Journal of Travel Research, 44(4), pp. $418-430$

12. George, B. P. (2005) Measuring tourist attachment to holidays: Some preliminary results. Tourism: An International Interdisciplinary Journal, 52(3), pp. 229-246

13. Go, F., W. Zhang (1997) Applying importance-performance analysis to Beijing as an international meeting destination. Journal of Travel Research, 35(4), pp. 42-49

14. GOI (Government of India, 1998) Report of the Seminar on Investment Opportunities in Tourism Sector in Kerala. Government of India Tourist Office, Kochi, pp. 15-17 
15. GOK (Government of Kerala, 2002) Tourist Statistics of Kerala. Department of Tourism, Government of Kerala.

16. GOK (Government of Kerala, 1995) Tourism Policy of Kerala. Department of Tourism, Government of Kerala.

17. GOK (Government of Kerala, 2000) Tourism Policy: Vision 2020. Department of Tourism, Government of Kerala

18. GOK (Government of Kerala, 2006a) Tourist Statistics of Kerala. Department of Tourism, Government of Kerala.

Board, Kerala.

19. GOK (Government of Kerala, 2006b) Economic Review. State Planning

20. Govindan, P. (1996) The 'Kerala model' of development: Development and sustainability in the Third World. Third World Quarterly, 17(5), pp. 941-958.

21. Gunn, C. A. (1994) Tourism Planning. New York, NY: Taylor \& Francis

22. Hall, C. M. (2000) Tourism Planning: Policies, Processes and Relationships. Harlow: Prentice Hall

23. Heath, E., G. Wall (1992) Marketing Tourism Destinations: A Strategic Planning Approach. New York: John Wiley and Sons

24. Hu, Y., B. Ritchie (1993). Measuring destination attractiveness: A contextual approach. Journal of Travel Research, 32(2), pp. 25-34

25. Hudson, S., G. W. H. Shepherd (1998) Measuring service quality at tourist destinations: An application of importance-performance analysis to an alpine ski resort. Journal of Travel and Tourism Marketing, 7(3), pp. 61-77

26. Kerala Tourism (2007) The Official Website of Tourism Ministry, Government of Kerala. URL: http://www.keralatourism.org (Accessed 01.11.2007)

27. Keyt, J. C., U. Yavas, G. Riecken (1994) Importance-Performance Analysis. International Journal of Retail and Distribution Management, 22(5), pp. 3540

28. Kokkranikal, J., T. Baum (2002) Human resources development for tourism in rural communities: A case study of Kerala. Asia Pacific Journal of Tourism Research, 7(2), pp. 64-76

29. Kokkranikal, J., A. Morrison (2002) Entrepreneurship and sustainable tourism: A case study of the houseboats of Kerala. Tourism and Hospitality Research, 4 (1), pp. 7-20.

30. Kotler, P., J. Bowen, J. Makens (2005) Marketing for Hospitality and Tourism, $4^{\text {th }}$ ed., NY: Pearson Education

31. Lawson, F. and B. M. Bovy, (1977) Tourism and Recreation Development. London: The Architectural Press

32. Levitt, T. (2004) Marketing myopia. Harvard Business Review, 82 (7/8), pp. $138-150$ 
33. Lew, A. (1987) A model of tourist attraction research. Annals of Tourism Research, 14(4), pp. 553-75

34. Lovelock, C., P. G. Patterson, R. H. Walker (1998) Services Marketing. Sydney: Prentice Hall

35. MacKay, K. J., D. R. Fesenmaier (1997) Pictorial element of destination in image formation. Annals of Tourism Research, 24(3), pp. 537-565

36. Martilla, J., J. James, (1977) Importance-performance analysis. Journal of Marketing, 41 (January), pp. 77-79

37. Martin, D. W. (1995) An Importance/Performance Analysis of service providers. Perception of Quality Service in the in the Hotel Industry, 3, pp. 5-17

38. Mayo, E. J., L. P. Jarvis (1981) Psychology of Leisure Travel. Boston: CABI Publishing.

39. National

Geographic

(2004).

URL:

http://www.nationalgeographic.com/traveler/index50.html (Accessed 19.07.2006)

40. Netto, N. (2004) Tourism development in Kerala. In Prakash, B.A. (Ed.) Kerala's Economic Development: Performance and Problems. New Delhi: Sage.

41. Nyberg, L. (1995) Determinants of the attractiveness of a tourism region. In Witt, S. F. and Moutinho, L.(Eds.) Tourism Marketing and Management Handbook. In UK: Prentice Hall, pp. 29-38

42. O’Neill, M. A., A. Palmer, S. Charters (2002) Wine production as service experience: Effects of service quality on wine sales. Journal of Services Marketing, 16(4), pp. 342-360

43. Parasuraman, A., V. A. Zeithaml, L. L. Berry (1985) A conceptual model of service quality and its implications for future research. Journal of Marketing, 49 (Fall), pp. 41-50

44. Pearce, D. G. (1979) Towards a geography of tourism. Annals of Tourism Research, 6 (3), pp. 245-272

45. Pike, S. (2002) Destination image analysis: A review of 142 papers from 1973 to 2000. Tourism Management, 23(5), pp. 541-549

46. Pushpangadan, K. (2003) Remittances, Consumption and Economic Growth in Kerala. Working Paper 343. Kerala, India: Centre for Development Studies.

47. Rajasenan, D., M. K. A. Kumar (2002) Demographic, psychographic and life-style characteristics of foreign tourists: an exploratory study of Kerala, India. Tourism Recreation Research, 29(3), pp. 51-59

48. Rao, N., K. T. Suresh, (2001) Domestic tourism in India. In Ghimire, K.B. (Ed.) The Native Tourist. London: Earthscan Publications Limited, pp. 198-228

49. Scott, D. R., C. D. Schewe, D. G. Frederick (1979) A multi-brand multiattribute model of tourist state choice. Journal of Travel Research, 17(1), pp. 23-29 
50. Sreekumar, T. T., P. Govindan (2002) Contentions and contradictions of tourism as development option: The case of Kerala, India. Third World Quarterly, 23(3), pp. 529-548

51. TCS (Tata Consultancy Services, 2000). Economic Benefits of Tourism Sector in Kerala. Report of the study conducted by TATA Consultancy Services, India.

52. Uysal, M., G. Howard, U. Jamrozy (1991) An application of ImportancePerformance Analysis to a ski resort: A case study in North Carolina. Visions in Leisure and Business, 10, pp. 16-25

53. Wade, D. J., P. F. J. Eagles (2003) The use of importance-performance analysis and market segmentation for tourism management in parks and protected areas: An application to Tanzania's national parks. Journal of Ecotourism, 2(3), pp. 196-213

54. Witt, C., A. Muhlemann (1995) Service quality in airlines. Tourism Economics, 1(1), pp. 33-49

55. WTO (World Travel Organization 1998). Tourism 2020 Vision Executive Summary. Madrid: WTO Publications Division

56. WTTC (World Travel and Tourism Council, 2002). The Travel and Tourism Satellite Account for Kerala: Impact of Travel and Tourism on the Jobs and the Economy. New Delhi: WTTC

57. WTTC (World Travel and Tourism Council, 2003). Executive Summary of the 2003 Travel and Tourism Economic Research. London: WTTC

58. Zeithaml V. A., L. L. Berry, A. Parasuraman (1993) The nature and determinants of customer expectations of service. Journal of the Academy of Marketing Science, 21 (1), pp. 1-12

RECEIVED: 09.12.2007

ACCEPTED: 16.01.2008 